\title{
A study of single-sided ventilation and provision of balconies in the context of high-rise residential buildings
}

\author{
Mohamed M. F. ${ }^{1,2, *}$, King S. ${ }^{2}$, Behnia M. ${ }^{3}$, Prasad D. ${ }^{2}$ \\ ${ }^{1}$ Faculty of Engineering and Built Environment, Universiti Kebangsaan Malaysia, Bangi, Malaysia \\ ${ }^{2}$ Faculty of the Built Environment, The University of New South Wales, Sydney, Australia \\ ${ }^{3}$ School of Mechanical Engineering, The University of Sydney, Sydney, Australia \\ * Corresponding author.Tel: +614 24898387,E-mail: farid0906@yahoo.com
}

\begin{abstract}
Passive design strategy is an important approach to reduce energy consumption of a building such as improving indoor thermal comfort through enhanced natural ventilation performance. This is crucial in achieving a more sustainable building especially for a tall high density residential development where energy consumption is huge. This paper looks into the potential of high-rise residential buildings to utilize abundant naturally available prevailing wind by mean of passive design strategy. Its objective is to investigate the potential to improve the ventilation performance of a single-sided ventilation strategy of high-rise residential buildings by introducing a series of balconies on their façades. Computational Fluid Dynamics (CFD) was used as a tool for investigation. Since CFD requires a validation process to investigate its reliability, existing wind tunnel experiments and empirical models were used in the validation process. This study found that an appropriate combination of balcony configurations and single-sided ventilation strategy could improve indoor ventilation performance of high-rise residential buildings; however, incorrect combination could further reduce the ventilation performance of an already inefficient ventilation strategy. Therefore, understanding the concept of single-sided ventilation strategy is crucial, and application of appropriate tools such as CFD is important to ensure ventilation performance optimization is achieved.
\end{abstract}

Keywords: Single-sided ventilation, Balcony, High-rise residential building, CFD.

\section{Nomenclature}

$Q \quad$ ventilation rate................................ $\mathrm{m}^{3} \cdot \mathrm{s}^{-1}$

A inlet opening area .................................. $\mathrm{m}^{2}$

$C_{D}$ discharge coefficient of opening.

$\Delta P$ pressure difference ............................. $N \cdot m^{-2}$

$C_{V}$ opening effectiveness............ dimensionless

$V \quad$ air velocity....................................... $m \mathrm{~s}^{-1}$

\section{Introduction}

The only solution to solve the human's basic need for shelter in urban environment through vertically constructed high-density residential buildings leads to either favorable or unfavorable impacts to the environment as well as to its occupants. There are various opportunities associated with high-density tall residential buildings such as optimization of land with less floor plinth, greater control of water and energy usage through central management, reduced transportation distance to workplaces, opportunities to waste recycling, utilization of natural lighting and ventilation for indoor environmental quality, etc. Therefore, vertical construction such as high-density residential building is an option of sustainable building approach if properly designed and managed.

This study looks into the potential of high-rise residential buildings to utilize naturally available prevailing wind. Optimization of the outdoor wind environment for indoor air quality and thermal comfort by mean of passive design strategies can reduce dependency on mechanical ventilation and, subsequently, reduces the energy consumption of buildings. Optimization of the prevailing wind for ventilation requires micro and macro investigations to ensure the objective of enhanced indoor airflow is achieved. This includes better understanding on the relationship between local wind climate and indoor ventilation performance. 
While cross ventilation strategy is a well accepted and recognized ventilation approach, the potential of single-sided ventilation strategy is always neglected by designers and policymakers. Coupled with a common provision of balconies in high-rise residential buildings, this paper discusses the relationship between single-sided ventilation strategy and the provision of balconies in the context of high-rise residential buildings. Therefore, the outlined objective of this paper is to discuss and investigate the potential to improve the ventilation performance of single-sided ventilation strategy of high-rise residential buildings by introducing a series of balconies on the façades of the buildings.

\section{Ventilation}

\subsection{Single-sided ventilation}

Ventilation strategies for building are categorized into two: single-sided ventilation and cross ventilation. In the context of this study, single-sided ventilation is defined as a condition where one or more openings exist only at one façade of a closed room or building, whereas, for cross ventilation, two or more openings are exist at two or more façades. Existence of an opening at more than one building facades in cross ventilation strategy potentially creates a much higher pressure gradient encouraging better natural ventilation performance. Therefore, generally, cross ventilation has a greater potential to manipulate the pressure gradient developed around buildings. However this is not the case for single-sided ventilation where it is limited to pressure gradient developed only at a single façade. Thus, ventilation performance of cross ventilation is always assumed to be better than single-sided ventilation. Despite the disadvantage of single-sided ventilation strategy in ventilation performance, it is still commonly used as a ventilation solution for apartments. This is due to various factors such as site constraint and unit number optimization. Since there is a greater potential of single-sided ventilation to fail in ventilating indoor residential spaces, but still, it is widely adopted as ventilation strategy in many residential apartments, greater understanding of its potential and limitation shall be attained to ensure that the potential of single-sided ventilation strategy is optimized and to avoid failure in indoor ventilation performance.

The ventilation performance of a single-sided ventilated apartment can be enhanced through appropriate façade treatments. There are various façade treatments and detailed building configurations which may change the pressure distribution across the building façades. For examples, the provision of balconies on the façade of a building as well as protruding and sunken floor plan layout. Complex façade treatment and floor plan result in a more complicated pressure distribution across building's façades and, consequently, causes changes in indoor ventilation performance. Therefore, these changes, if positively utilized, can enhance indoor ventilation performance by optimizing the available prevailing wind.

\subsection{Balcony as a passive design strategy}

Balcony is defined as "a platform projecting either from an inside or an outside wall of a building” [1]. A balcony can provide various benefits from the aspects of social, economy and environmental, for examples, it provide private outdoor spaces, enhanced the monetary value of a building and provides protection from extreme outdoor climate, respectively [2,3]. There are many studies on the impact of balcony on airflow [3, 4, 5, 6]; however, none of researchers looking into the affect of the provision of balcony on the performance of singlesided ventilation strategy in the context of tall buildings. Since a provision of balconies could change the pressure distribution on the façades of a building $[4,6]$, it is seen as a potential 
which can be utilized to induce indoor ventilation performance of single-sided ventilated buildings.

\section{Methodology}

Computational fluid dynamics (CFD) is the main tool for this study which has been widely used to predict indoor ventilation performance. However, CFD comes with two great setbacks: it requires huge computational effort and validation and verification process. With current advances in computer technology and greater affordability, CFD has been widely used by researchers such as van Hooff and Blocken [7] and Cheng et al. [8] to investigate ventilation performance of large buildings.

There are various approaches to predict indoor ventilation performance for tall buildings. The followings are commonly used approaches:

A. Combination of small-scale models and empirical models (Approach A).

B. Combination of CFD models with empirical models (Approach B).

C. Coupled CFD simulation (Approach C).

D. De-coupled CFD simulation (Approach D).

According to Jiru and Bitsuamlak [9], Approach C is a preferred approach compare to Approach D since the accuracy of Approach D can easily be compromised though it gives an advantage of lower computational effort. Among all the approaches, only Approach D was excluded in this study, while the others were used to predict ventilation rate. Empirical models used for the validation study were Equation 1 [10] and Equation 2 [11]. The value of discharge coefficient of opening, $C_{D}$, used for this study was 0.5 since the opening area was less than $10 \%$ of the area of the façade. In the case of single opening, the inlet area, A, was taken to be half of the opening, and the reference pressure is taken to be at the middle of the inlet. For Equation 2 the value of opening effectiveness, $C_{V}$, was 0.025 .

$$
\begin{aligned}
& Q=C_{D} \cdot A \cdot \sqrt{(2 \cdot \Delta P / \rho)} \\
& Q=C_{V} \cdot A \cdot V
\end{aligned}
$$

This study utilized existing wind tunnel experimental data [12] to validate its results with initial validation study for cross ventilation strategy with perpendicular wind direction which was completed earlier [13]. An additional validation study for single-sided ventilation strategy (wind angle $45^{\circ}$ only) and cross ventilation strategy $\left(0^{\circ}\right.$ and $\left.45^{\circ}\right)$ was completed, where Approach C was validated against Approach A and Approach B.

\subsection{Computational Fluid Dynamics (CFD)}

This study used commercial code CFD software which was Ansys CFX 12.0. The turbulence model used is standard k-epsilon turbulence model. The turbulence model was selected due to its robustness which was important in this complex and huge coupled outdoor and indoor simulation study though it may be less accurate in areas with vortex shedding $[14,15]$. It was a steady-state CFD simulation simulated under isothermal condition where the effect of buoyancy force on ventilation was not included. Mesh independence study is an important procedure in CFD simulation to understand the simulation accuracy as well as to optimize computational effort. Since this paper is a subsequent study to the previous investigation [13] which uses similar overall building forms, mesh independence study and the setup of computational domain were not discussed in this paper. The maximum number of element 
used in this study was around $2.4 \times 10^{7}$ which consists of mainly tetrahedral mesh except at the ground of outdoor domain where prism shape was used. Tetrahedral mesh was selected due to its robustness where it can easily mesh all building configurations used in this study.

\subsection{Simulation setup and model configurations}

Table 1. A list of case studies tested.

\begin{tabular}{ccccc}
\hline Test case & Ventilation strategy & No. of opening & Façade treatment & Wind angle \\
& & & & \\
\hline Case 1 & Cross & 2 & Flat & $0^{\circ}$ \\
Case 2 & Single-sided & 1 & Flat & $0^{\circ}$ \\
Case 3 & Single-sided & 1 & Balcony $(1.5 \mathrm{~m})$ & $0^{\circ}$ \\
Case 4 & Single-sided & 2 & Balcony $(1.5 \mathrm{~m})$ & $0^{\circ}$ \\
Case 5 & Cross & 2 & Flat & $45^{\circ}$ \\
Case 6 & Single-sided & 1 & Flat & $45^{\circ}$ \\
Case 7 & Single-sided & 1 & Balcony $(1.5 \mathrm{~m})$ & $45^{\circ}$ \\
Case 8 & Single-sided & 2 & Balcony $(1.5 \mathrm{~m})$ & $45^{\circ}$ \\
\hline
\end{tabular}

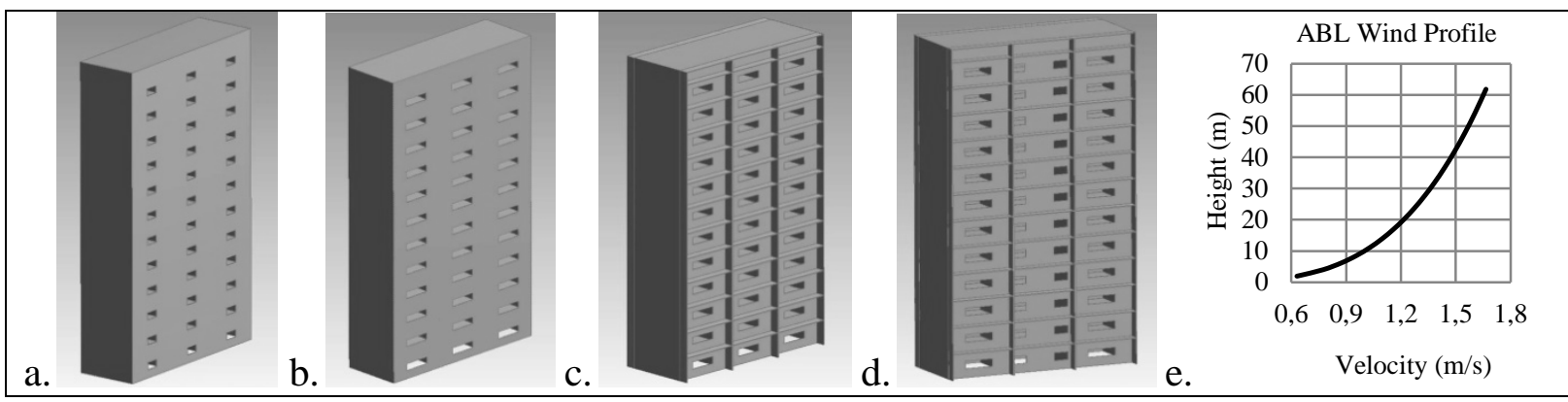

Fig. 1. The building configurations for Case land 5 (a), Case 2 and 6 (b), Case 3 and 7 (c) and Case 4 and $8(d)$, together with $A B L$ wind profile with mean speed exponent of $0.28(e)$.

This study used the building configuration similar to the models used in wind tunnel experiment by Ismail. The overall dimension of the model was $30 \mathrm{~m}$ (width) x $50 \mathrm{~m}$ (height) $\mathrm{x}$ $10 \mathrm{~m}$ (depth) to resemble 36 units apartment with 12-storey height. Three units were located at each floor with floor to floor height is $4 \mathrm{~m}$. While Ismail's models did not include opening an indoor space, this study provided a single or double openings (Fig. 1). The dimension of the opening was $4.4 \mathrm{~m}$ (width) $\mathrm{x} 1.15 \mathrm{~m}$ (height) for setup with single opening, and $2.2 \mathrm{~m}$ (width) $\mathrm{x}$ $1.15 \mathrm{~m}$ (height) each for double openings located at a single façade or at two opposite façades. The total opening area provided at each unit was $5.06 \mathrm{~m}^{2}$, which was approximately $5 \%$ of the floor area. This study only focused on units located at the middle.

\section{Analysis and Findings}

\subsection{Validation Study}

Fig. 2 and Fig. 3 (see below) show that CFD predictions of wind pressure on facades of a building were inaccurate at areas located at the bottom leeward of the building where CFD over predicts the values of wind pressures. Therefore, if the wind pressure data were used in Approach B to predict indoor ventilation rate, it will result in under prediction on units located at the bottom of the building. The figures also suggest that if Approach $C$ is used, it might also result in under prediction of indoor ventilation rate for lower units. Generally, the wind pressure distribution predicted by CFD was found to be acceptable. 


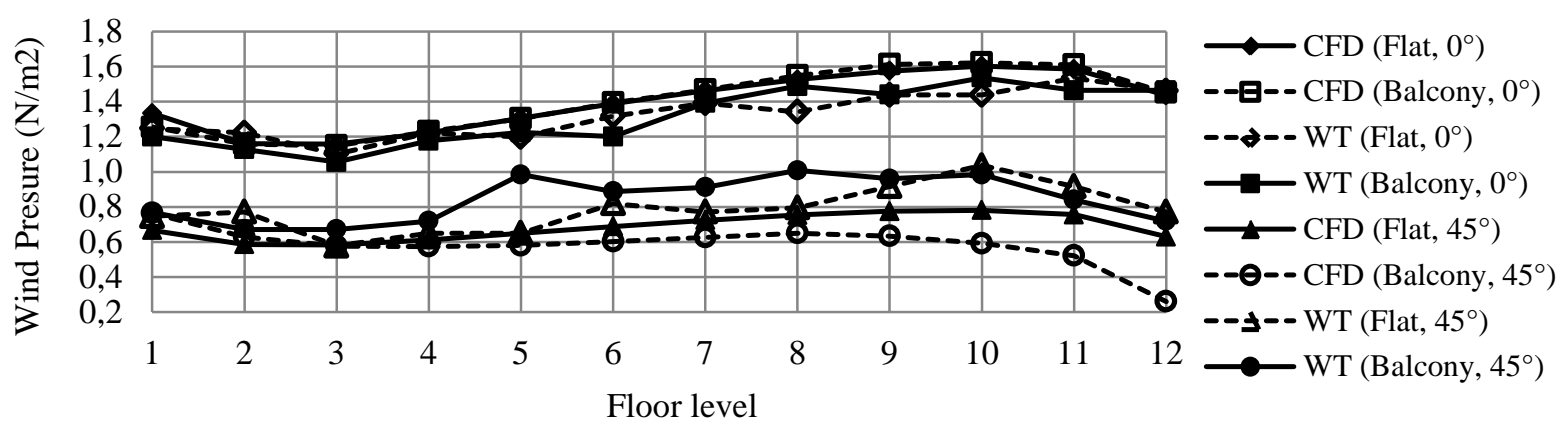

Fig. 2. Windward wind pressure distributions for flat façade and façades with balconies (opening is not provided).

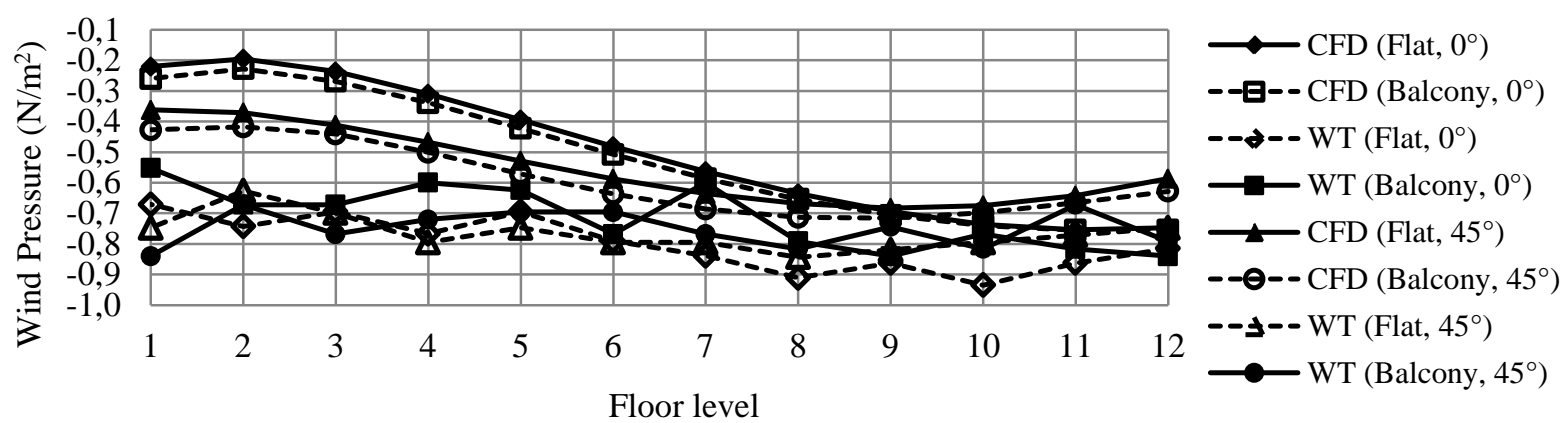

Fig. 3. Leeward wind pressure distributions for flat façade and façades with balconies (opening is not provided)



Fig. 4. Predicted ventilation rates for Case land Case 5 using Approach $A, B$ and $C$.

For cross ventilation strategy (Fig. 4), it was found that Approach B and Approach C provided acceptable ventilation rate predictions for $0^{\circ}$ wind angle with the worst prediction occurs at units located at lower floors. The average inaccuracies for Approach $\mathrm{B}$ and Approach $\mathrm{C}$ were found to be $6 \%$ and $12.5 \%$, respectively. The inaccuracy at the lower level was expected due to the difficulty of the selected turbulence model to predict the recirculation zone at the bottom leeward side of the building.

For wind angle of $45^{\circ}$, it was found that Approach B and Approach $\mathrm{C}$ under predict indoor ventilation performance in comparison to Approach A, with the average inaccuracies of $24 \%$ and $11 \%$, respectively. It was also found that the inaccuracies were relatively similar to all units. These greater inaccuracies can be due to the fact that the value of discharge coefficient of opening, $C_{D}$, used was 0.5 even though the wind direction close to the opening is travelling almost parallel to the facade of the building which shall suggests that the value may not be appropriate and shall be lower. This is supported by Equation 2 which suggests that the ventilation rate for wind angle of $45^{\circ}$ shall be between 50 to 70 percent of the ventilation rate for $0^{\circ}$ wind angle based on the suggested values of opening effectiveness, $\mathrm{C}_{\mathrm{V}}$, by ASHRAE 
[11] (ASHRAE suggests the value to be $0.25-0.35$ for $45^{\circ}$ and $0.5-0.7$ for $0^{\circ}$ ). This is also supported by an experiment completed by Larsen and Heiselberg [16] which found that the ventilation rate for a cross ventilated single cell building at $45^{\circ}$ wind angle is reduced by around $55 \%$ in comparison to $0^{\circ}$.

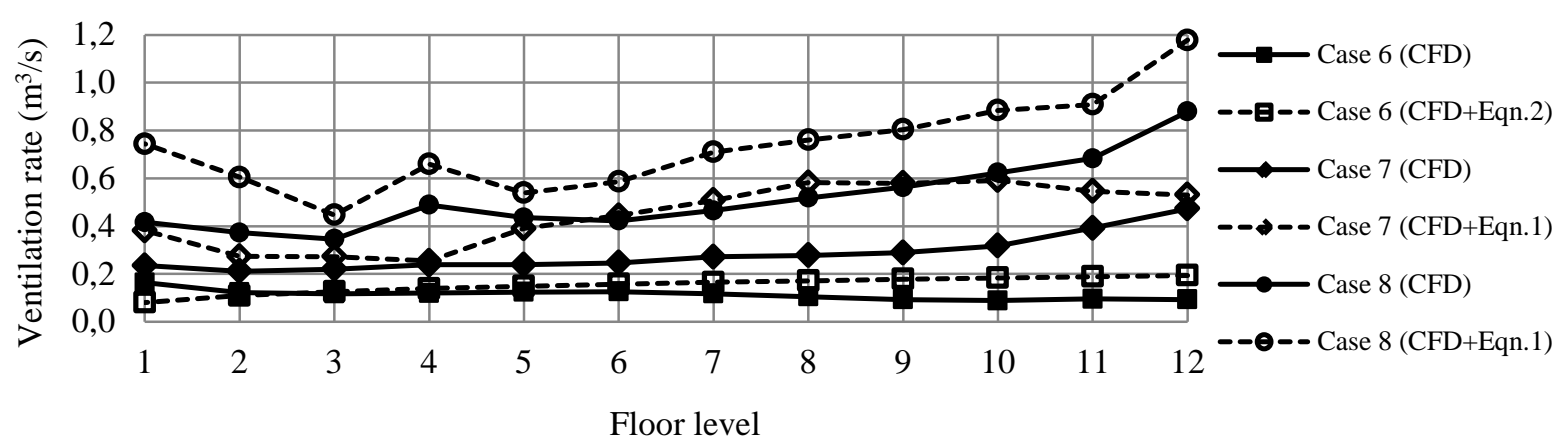

Fig. 5. Predicted ventilation rates for Case 6, 7 and 8 using Approach B and C.

In the case of single-sided ventilation strategy, only wind direction of $45^{\circ}$ was used for validation study. For Case 6, Approach B with Equation 2 was used. Approach B with Equation 1 was used for Case 7 and Case 8 assuming that the CFD wind pressure difference across two reference point is acceptably describing the reality though it may come with some inaccuracies. Even though, both approaches might have not provided accurate predictions due to being applied to a difference building context, more or less, it shall give some idea on the ventilation rate. Fig. 5 shows that Approach $C$ under predicted ventilation rate for all cases. The average percentage of difference between Approach $C$ and Approach B for Case 6, 7 and 8 were $25 \%, 45 \%$ and $30 \%$, respectively. Though the prediction differences for the values of ventilation rate were found to be high, Approach $\mathrm{C}$ was found to acceptably predict ventilation rate improvement due to changes on façade treatment.

Validation of single-sided ventilation strategy for building with $0^{\circ}$ wind angle was not performed in this study. This is due to the limitation of Equation 1 and Equation 2 in predicting single-sided ventilation for the building configuration under the $0^{\circ}$ wind angle. For example, in Equation 1, two reference pressures (if taken at a midpoint of each opening) are equal or almost equal, thus prediction of ventilation rate is zero or almost zero. In reality, this is not the case since there is a distinct pressure difference across each of the openings, thus inlet and outlet exist within the opening itself. On the other hand, Equation 2 is not appropriate due to the immediate outdoor air characteristic of airflow is different from low rise building where the equation is normally used and derived from. Thus, it was assumed that if Approach $\mathrm{C}$ was acceptably validated in earlier validation studies, the approach should also give an acceptable prediction under the $0^{\circ}$ wind angle.

\subsection{Ventilation Rate for Various Façade Treatments}

Fig. 6 (see below) shows that cross ventilation strategy was far more effective in comparison to single-sided ventilation strategy. Cross ventilation strategy was also able to optimize the increased wind speed at upper floors. However, this was not the case for single-sided ventilation trategy with wind direction of $0^{\circ}$ wind angle. This finding shows that under the circumstances, the ventilation performance of units located at upper units was relatively lower than units at the lower floor. This was due to the units being located within the stagnation zone, where the pressure difference across the facades was very low (see Fig. 2). Under $0^{\circ}$ wind angle, the provision of balconies (Case 3) was also found to reduce indoor ventilation 
performance of single-sided ventilated apartments, however, by splitting the opening into two (Case 4), it slightly increased the ventilation performance.

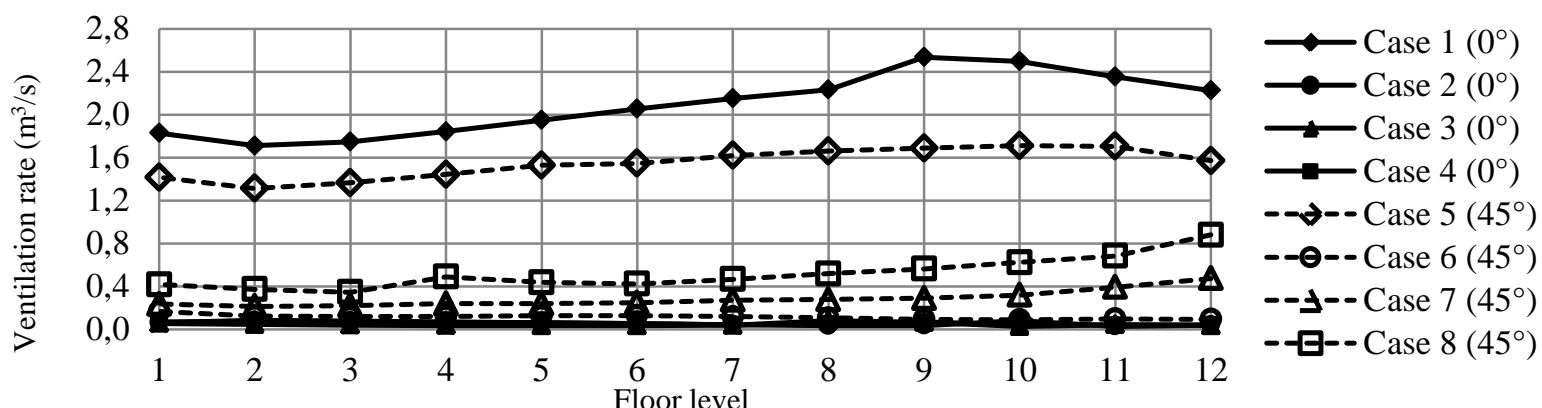

Fig. 6. Comparison between predicted ventilation rates for Case 1 to 8 using Approach $C$.

In the other hand, in the case of $45^{\circ}$ wind angle, it was found that ventilation performance of single-sided ventilation strategy was improved in comparison to $0^{\circ}$ wind angle, while for cross ventilation strategy, it was slightly reduced. For units with a balcony, their ventilation performances were higher than units with flat façade. This was due to external airflow travelling almost parallel to the openings at the building with flat façades, thus reducing its impact on ventilation performance. Additional to this, with a simple reconfiguration of opening from a single opening to double openings located close to protruding vertical walls of a balcony (Case 8), it has enhanced indoor ventilation rate by almost four times the ventilation performance of the model with a single opening with flat façade (Case 6).

\section{Conclusions}

Being a less effective ventilation strategy, single-sided ventilation strategy should be adopted in building design with clear understanding of its effectiveness and potential. This study found that cross ventilation strategy is a preferred option. However, if single-sided ventilation strategy is the only option, its ventilation performance effectiveness can be improved with appropriate façade reliefs such as a balcony. Below are the findings on the potential of balconies to enhance ventilation performance of single-sided ventilation strategy for tall buildings:

a. Perpendicular wind towards the façade of a tall building shall be avoided, where an introduction of a series of balconies could reduce indoor ventilation performance. This can be observed in Case 3. Under this wind condition, it is found that the balconies act as a buffer protecting the indoor spaces from direct penetration of wind.

b. For $45^{\circ}$ wind angle, it was found that the provision of balconies, such as in Case 7 and Case 8, significantly improve indoor ventilation performance in comparison to a flat façade building (Case 6). However, the improvement shown in Case 7 and Case 8 was still much lower than Case 5, which adopt cross ventilation strategy.

c. Opening configuration plays an important role to improve an indoor ventilation performance. An appropriate combination of a balcony and opening configurations improves indoor ventilation performance (Case 8); otherwise, it reduces the indoor ventilation performance (Case 7).

\section{References}

[1] H. J. Cowan, \& P. R. Smith, Dictionary of architectural and building technology. 4th ed. London: Spon Press (Taylor \& Francis Group), 2004, p. 24. 
[2] M. F. Mohamed, M. Mohd Tahir, \& D. Prasad, A study on balcony and its potential as an element of ventilation control in naturally ventilated apartment in hot and humid climate. Proceedings of International Conference on Construction and Building Technology (ICCBT 2008), 2008, pp. 173 - 180.

[3] N. Papamanolis, An overview of the balcony's contribution to the environmental behaviour of buildings. Proceedings of The 21th Conference on Passive and Low Energy Architecture (PLEA2004), 2004.

[4] I. Chand, P. K. Bhargava, \& N. L. V. Krishak, Effect of balconies on ventilation inducing aeromotive force on low-rise buildings. Building and Environment, 33, 1998, pp. 385396.

[5] E. Prianto, \& P. Depecker, Characteristic of airflow as the effect of balcony, opening design and internal division on indoor velocity: A case study of traditional dwelling in urban living quarter in tropical humid region. Energy and Buildings, 34, 2002, pp. 401409.

[6] H. Kotani, \& T. Yamanaka, Wind pressure coefficient and wind velocity along building wall of apartment building with balcony. 6th International Conference on Indoor Air Quality, Ventilation \& Energy Conservation in Buildings - IAQVEC 2007, 2007.

[7] T. Van Hooff, \& B. Blocken, Coupled urban wind flow and indoor natural ventilation modelling on a high-resolution grid: A case study for the Amsterdam Arena stadium. Environmental Modelling \& Software, 25, 2010, pp.51-65.

[8] C. C. K. Cheng, K. M. Lam, R. K. K. Yuen, S. M. Lo \& J. A. Liang, study of natural ventilation in a refuge floor. Building and Environment, 42, 2007, pp. 3322-3332

[9] T. E. Jiru, \& T. Bitsuamlak, Advances in applications of CFD to natural ventilation. The Fifth International Symposium on Computational Wind Engineering (CWE2010). 2010.

[10]R. M. Aynsley, W. Melbourne \& B. J. Vickery, Architectural aerodynamics, London, Applied Science Publisher Ltd, 1977, pp. 189 - 194.

[11]ASHRAE 1997. ASHRAE Handbook: Fundamentals, Atlanta, American Society of Heating, Refrigerating and Air-Conditioning Engineers, Inc. 1997, p. 25.13.

[12] A. M. Ismail, Wind-driven natural ventilation in high rise buildings with special reference to the hot humid climate of Malaysia. Phd Thesis, University of Wales College of Cardiff, 1996.

[13]M. F. Mohamed, S. King, M. Behnia, D. Prasad \& J. Ling, Wind-driven natural ventilation study for multi-storey residential building using CFD. Proceedings of 44th Annual Conference of the Australian and New Zealand Architectural Science Association, 2010.

[14]R. Yoshie, A. Mochida, Y. Tominaga, H. Kataoka, K. Harimoto, T. Nozu \& T. Shirasawa, Cooperative project for CFD prediction of pedestrian wind environment in the Architectural Institute of Japan. Journal of Wind Engineering and Industrial Aerodynamics, 95, 2007, pp. 1551-1578.

[15]S. H. L. Yim, J. C. H. Fung, A. K. H. Lau \& S. C. Kot, Air ventilation impacts of the "wall effect" resulting from the alignment of high-rise buildings. Atmospheric Environment, 43, 2009, pp. 4982-4994.

[16]T. S. Larsen \& P. Heiselberg, Single-sided natural ventilation driven by wind pressure and temperature difference. Energy and Buildings, 40, 2008, pp. 1031-1040. 